\title{
The Effectiveness of Visuo- Motor Behavior Rehearsal (VMBR) to Reduce the Anxiety and to Improve Self Concept for Athletes with Special Needs
}

\author{
Aziz Ahmed Alrahamneh \\ Special Education Department, Al-Balqaa' Applied University \\ Al-Salt, Jordan \\ E-mail: azizar09@yahoo.com \\ Hayfa Tayseer Elbokai (Corresponding author) \\ Special Education Department, Al-Balqaa' Applied University \\ Tabarboor- Salman Ben aby Rabeea' Street, 11947, B.O.Box: 1490 \\ Al-Salt, Amman, Jordan \\ E-mail: hayfaelbokai@yahoo.com
}

Received: August 13, 2011

Accepted: September 1, $2011 \quad$ Published: December 1, 2011

doi:10.5539/ijps.v3n2p276

URL: http://dx.doi.org/10.5539/ijps.v3n2p276

\begin{abstract}
This study was an eight-week, 12-session experiment designed to examine the effect of Visuo-Motor Behavior Rehearsal (VMBR) on the athletes with special needs. Subjects were 63 male and female athletes from Jordanian disabilities national teams ranging in age from 20 to 35. Based on a pre-assessment of subjects' anxiety and self-control scales, the experimental group assigned to experimental conditions VMBR. Post-assessment data for experimental performance was analyzed by means of two groups. A significant main effect for the experimental group was observed, indicating that, there was a significant improvement in self-concept and low anxiety from pre- to post-assessment.
\end{abstract}

Keywords: Visual disability, Motor disability, VMBR, Athletes, Special needs

\section{Introduction}

Educational literature indicate that people with disabilities more tense than normal, due to physical and psychological problems, as well as negative social situation in which they find themselves in, and therefore relaxation fits this category significantly. There are several forms of relaxation, such as increased relaxation, yoga, Taishi, rhythmic exercises, visualization or imagination (Ibrahim \& Farhat, 1998).

The provision of psychological skill training for athletes has become a widely accepted practice (Petrie \& Diehl, 1995). Previews have led to optimistic conclusions about the potential for psychological skill training in sports (Feltz \& Landers, 1983; Murphy \& Jowdy, 1992; Vealey \& Walter, 1993). One psychological skill package, visuo-motor behavioral rehearsal (VMBR), was developed by Suinn (1972; 1976). Components of VMBR include relaxation training, visualization or mental imagery, and performance of the skill in a simulated stressful environment. These components provide the foundation of most psychological skill training programs used in sport psychology applications.

VMBR has been the subject of several experimental evaluations. For example, Weinberg, Seabourne, and Jackson (1981) compared the effects of relaxation training, imagery training, VMBR training and a placebo control on karate performance. The VMBR condition demonstrated significantly improved karate performance and decreased pre-competition state anxiety. Hall and Erffmeyer (1983) tested VMBR with women intercollegiate basketball players. They found that VMBR lead to significantly improved foul shooting. Gray (1990) end Andre and Means (1986) found that VMBR training lead to improved racquetball and Frisbee tossing performance, respectively. Overall, the evidence for VMBR has been supportive. However, the studies of VMBR and performance enhancement techniques generally have been weak with respect to external validity, utilizing 
participants and/or performance tasks that are often removed from the situations for which such training is most often advocated: moderately to highly-skilled athletes engaging in competitive sport. Murphy and Jowdy (1992) raised the same concern in the conclusion of their chapter on imagery and mental practice. They noted that staining programs have been offered to a variety of elite athletes "...but the effects of such training programs have yet to be evaluated" (p. 245). The application of mental training programs has clearly outstripped the research base. The present study attempted to help fill this void in the performance enhancement literature by examining the efficacy of a psychological skills package with special needs athletes who were participating in a variety of sport activities.

We also attempted to extend the performance enhancement literature by exploring the potential for psychological skill training when self-administered by the athlete with special needs. We use a VMBR method not only to reduce the level of anxiety, but also to improve self concept for athletes with special needs. Also, this method can be a method of psychotherapy in general.

We recognized the importance of unconscious, and everything happen in conscious level such as convictions and experiences would stored in the unconscious to become an important part of an individual's personality. Conscious is a way to influence the unconscious through self-control and to suggest it, auto-suggestion is the way to change the unconscious life (Hejaze, 2005). Our knowledge and understanding that our actions, our feelings, and behaviors are the results of our imaginary and perceptions would give us the motivation to change our personalities, which opens the psychological door to gain the skills and success.

The VMBR is established on the fact that the former imagination to perform the function or work before actually performance can make this work easier and more precise, also man would be able with imagination exercises to make physical and intellectual achievements, beyond the limits of his real physical and intellectual abilities. From this side, this technique is very important for physical training because the player standing the competition in his mind before the actual competition, and this is what vivid imagery seeks to. The VMBR has been applied to make the player train under real match conditions. This method is used during the 1976 Olympics to create similar conditions to those faced by players during real games, also it used to train on mental coordination.

The purpose of this study was compared the experimental group to control group by using VMBR. Also. Detect differences in the anxiety level and self-concept scales between experimental groups to control group in the post-assessment.

We hypothesized that sport performance would increase significantly more in the VMBR condition than in control condition. A secondary hypothesis was that competitive anxiety would decrease significantly more for VMBR participants than for control participants. This was expected because of the inclusion of relaxation training in the package. Also, we expected that self-Control would increase significantly more for VMBR participants than for control participants. Finally, we expected that anxiety would decrease but self-concept would increase for physically disabled than for visually impaired.

\section{Literature Review}

\subsection{Effects of Self-administered Visuo-motor Behavioral Rehearsal on Sport Performance of Collegiate Athletes}

The effects of self-administered visuo-motor behavioral rehearsal (VMBR) training on athletic performance was investigated. Participants were 36 male and female collegiate athletes representing seven sports. Results indicated that the VMBR group exhibited significantly greater increases in sport performance than did the delayed-training control group. A significant decrease in sport competition anxiety was also observed for the VMBR group. If replicable, these data suggest the availability of self-administered psychological skill training program for athletes, coaches and sport psychologists who seek an adjunct or alternative to traditional training (Lohr \& Scogin, 1998, P.P. 206-213).

\subsection{The Effect of Visuo-motor Behavior Rehearsal (VMBR) and Videotaped Modeling (VM) on the Three-throw} Performance of Intercollegiate Athletes

This study was a three-week, 15-session experiment designed to examine the effect of Visuo-Motor Behavior Rehearsal (VMBR) and Videotaped Modeling (VM) on the free throw accuracy of male intercollegiate athletes. Subjects were 48 male athletes ranging in age from 18 to $25(\mathrm{M}=19.8)$. Based on a pre-assessment of subjects' free throw shooting ability, subjects were placed in either High or Low ability categories, matched, and then assigned to one of three experimental conditions: (1) VMBR, (2) VMBR+VM, (3) VM. Post-assessment data for free throw shooting performance was analyzed by means of a two (condition, ability level) by one (time) factor ANOVA. A significant main effect for the within subjects factor time was observed, indicating that, across the levels of condition and ability, there was a significant improvement in free throw shooting from pre- to 
post-assessment. It is argued that a number of nonspecific factors common to each of the experimental conditions were responsible for the demonstrated improvement in free throw shooting (Onestak, 1997, P.P. 185-214).

\subsection{The Role of Mental Imagery and Emotion in Imagined Interaction}

Imagined interactions, internal dialogues experienced as conversations with significant others, are conceptualized as a form of social cognition. Imagined interactions have important affective components and mental imagery. Results of an investigation demonstrate that verbal imagery is associated with self-dominance, rehearsal and understanding while visual imagery is associated with more pleasantness. Pleasant imagined interactions are lower in self-dominance and more similar to actual communication than unpleasant imagined interactions. The results are explained in terms of information processing and relational communication; two categories of imagined interaction reflecting verbal and mixed imagery are also proposed (Zagacki, Edwards, Honeycutt, 1992, P.P.56-68).

\subsection{Does Motor Imagery Training Improve Hand Function in Chronic Stroke Patients, A Pilot Study}

OBJECTIVE: To assess the efficacy of motor imagery training for arm function in chronic stroke patients. The relation between mental processes such as attentional and perceived personal control over recovery, and motor imagery was additionally investigated. DESIGN AND SUBJECTS: Twenty patients with long-term motor impairments (mean two years post stroke), were assessed before and after four weeks of training. Ten patients mentally rehearsed movements with their affected arm. Their recovery was compared with patients who performed non-motor imagery $(n=5)$, or who were not engaged in mental rehearsal $(n=5)$. SETTING: Patients were recruited from the stroke database of Ninewells Hospital, Dundee. Assessment and training were performed at the patients' home. INTERVENTIONS: The motor imagery group was asked to practice daily imagining moving tokens with their affected arm. The non-motor imagery group rehearsed visual imagery of previously seen pictures. All patients practiced physically moving the tokens. MAIN MEASURES: The following variables were assessed before and after training: motor function (training task, pegboard and dynamometer), perceived locus of control, attention control and ADL independence. RESULTS: All patient groups improved on all motor tasks except the dynamometer. Improvement was greater for the motor imagery group on the training task only (average of 14\% versus 6\%). No effect of motor imagery training was found on perceived or attentional control. CONCLUSIONS: Motor imagery training without supervision at home may improve performance on the trained task only. The relation between movement imagery, attention and perceived personal control over recovery remained unclear(Dijkerman; Ietswaart ; Johnston ; MacWalter, 2004, P.P. 538-549).

\section{Methods}

\subsection{Participants}

Participants were 63 male and female athletes with special needs including physically and visually impaired recruited from a Jordanian disabilities national teams, ranging in age from 20 to 35. Participants purposely chose to include only disabilities national team athletes because of poor studies with this special group. Participants divided into two groups: experimental group 32 subjects, control group 31 subjects.

\subsection{Material}

\subsubsection{Anxiety Test}

To assess anxiety, the Zawawi's anxiety test (1991) was used. The anxiety test is a 35-item self-report instrument. Items were scored on 5-point Likert-type scale. The range of scores was from 35 (low anxiety) to 180 (high anxiety). Evidence for the item discriminability, internal consistency, content validity, and concurrent validity of Anxiety scale have been reported (Zawawi, 1991). The total score from the 35 items was used as the dependent variable.

\subsubsection{Tennessee Self-Concept Scale (TSCS)}

Consists of 75 self-descriptive items by means of which an individual portrays what he or she is, does, likes, and feels. The scale is intended to summarize an individual's feeling of self-worth, the degree to which the self-image is realistic, and whether or not that self-image is a deviant one. Evidence for the item discriminability, internal consistency, test re-test, content validity, and concurrent validity of the TSCS have been reported (Mohammed, 1991). The total score from the 75 items was used as the dependent variable.

\subsubsection{Motor Perception and Auto- suggestion}

We set up a training program depends on the training of the player on the process of relaxation and imagination. We focus on the configuration mentality of the player and re-construction of his knowledge and use the 
suggestion, then comes the role of VMBR as invented by Suinn, which including simple exercises and examples. Section one focused on relaxation training. The technique was based on Jacobson's (1938) progressive muscle relaxation and included learning the use of cue-control signals to tense and relax. Section two concentrated on aspects of visualization including visualizing a successful competition scene. Finally, section three put the relaxation and visualization skills together for VMBR for specific performance enhancement. Included in this section were details in choosing a specific competition performance scene.

\subsection{Procedure}

Assessments took place at scheduled interviews held in a quiet area of the Jordan Federation for Disabilities athletes. All participants (VMBR training group and control group) completed the pre-test assessment- TSCS and anxiety scale.

Then, each Participants in the VMBR training group, was asked to sit comfortably, close his/her eyes, take a deep breath to relax, and visualize an aspect of their last performance from start to finish. During the training section we use the Mona moor music and auto-suggestion. After visualization had ended, each participant discussed about his/her feelings and visualization. All participants' initial sport performance was objectively assessed according to each particular sport and the aspect of the sport the participant chose to enhance. In addition, participants were telephoned weekly during the training period to check progress and answer any questions. They were encouraged to follow the training and complete the 12-day training within eight weeks.

All participants (VMBR training group and control group) completed the post-test assessment- TSCS and anxiety scale.

\section{Result}

\subsection{Performance}

Means and standard deviations for the dependent measure at the pre-and post-test times of assessment for the two conditions are presented in Table 1. A two-sample t-test was computed to assess percentage change in sport performance between the experiment and control groups.

\subsection{Anxiety}

Results indicated that no significant differences between the experimental group and control group in the pre-test assessment $\mathrm{t}(63)=1.96, \mathrm{p}<.05$.

But results indicated that the VMBR group had significantly lower anxiety compared to the control group at the end of the training period, $\mathrm{t}(63)=5.53, \mathrm{p}<.01$. The direction of the means indicated that the VMBR groups had reduced anxiety from pre-to post-training, whereas the control group increased on this measure.

Also, the results indicated that there is a significant differences between the physically disabled and visually impaired with experimental group and control group in the post-test assessment t $(32)=5.07, \mathrm{p}<.01$. The direction of the means indicated that the physically disabled had reduced anxiety as presented in table 2 .

\subsection{Self-Concept}

Results indicated that no significant differences between the experimental group and control group in the pre-test assessment for the self concept $\mathrm{t}(63)=1.6, \mathrm{p}<.05$.

But results indicated that the VMBR group had significantly more self-concept compared to the control group at the end of the training period, $t(63)=3.52, \mathrm{p}<.01$. The direction of the means indicated that the VMBR groups had more self concept from pre-to post-training, whereas the control group decreased on this measure.

Also, the results indicated that there is a significant differences between the physically disabled and visually impaired with experimental group and control group in the post-test assessment t $(32)=3.31, \mathrm{p}<.01$. The direction of the means indicated that the physically disabled had more self concept as presented in table 2 .

\section{Conclusion}

The primary concern of this study was whether those who have the VMBR training would improve their sport performance compared with the control group. Results indicated that the VMBR group performed significantly better in their chosen aspect of performance than the control group. These findings are consistent with Gray (1990), Noel (1980), and Weinberg et al. $(1981 ; 1982)$ who found that VMBR practice was effective in enhancing certain areas of sport performance.

Results indicated that the VMBR group had a significant reduction in anxiety and more self concept. Examination of the group means showed an increase in anxiety for the control condition and decrease in self 
concept. Data showed that the training not only decreased anxiety, but prevented an increase in anxiety, perhaps due to the progression of the athletic season into more important competition (e.g., SEC and NCAA events). Also perhaps due to VMBR program, which had a positive impact in reducing anxiety and rising self concept, in addition to practicing relaxation exercises, and individual meetings for the athletes.

In addition to the significant enhancement in performance, results indicated that the physically disabled had a significant reduction in anxiety and a significant rise in self concept. Examination of the group means showed an increase in anxiety and decrease in self concept for the visually impairment, perhaps due to ability for physically disabled to imagine more than the visually impairment do. Also, may be because of the low number of the visually impairment sample.

In conclusion, the results of the present investigation lend support for the effectiveness of VMBR. It should be noted that the present study dealt only with athletes with tow kinds in special needs. Future research will need to be conducted to other kinds in special needs, and if the VMBR package will also enhance the performances of less-skilled athletes.

\section{References}

Dijkerman HC. Ietswaart M. Johnston M., \& MacWalter RS. (2004): Does motor imagery training improve hand function in chronic stroke patients? A pilot study. Clinical Rehabilitation, 2004, Aug, 18(5): 538-49 (30ref).[Online] Available: http://search.ebscohost.com/login.aspx?direct=true\&db=rzh\&AN=2005013145\&site=ehost-live

Ebrahem, H., \& Farhat, L. (1998). Sport education for disabilities. Cairo: Arabic Feker Press.

Feltz, D., \& Landers, D. (1983). The effects of mental practice on motor skill learning and performance: A meta-analysis. Journal of Sport Psychology, 5, 25-57

Gray, S.W. (1990). Effect of visuomotor rehearsal with videotaped modeling on racquetball performance of beginning players. Perceptual and Motor Skills, 70, 379-385. http://dx.doi.org/10.2466/PMS.70.2.379-385

Hall, E.G., \& Erffmeyer, E.S. (1983). The effects of vi-quo-motor behavioral rehearsal with videotaped modeling on free throw accuracy of intercollegiate female basketball players. Journal of Sport Psychology, 5, 343-346

Hejaze, A. (2006): Intellectual suggestion. Amman: Cultural World Press.

Jacobson, F. (1938). Progressive relaxation. Chicago: University of Chicago Press.

Lohr, A., \& Scogin, F. (1998). Effects of self-administered visuo-motor behavioral Rehearsal on Sport Performance of Collegiate Athletes. Journal of Sport Behavior, 21(2). [Online] Available: http://search.ebscohost.com/login.aspx?direct=true $\& \mathrm{db}=\mathrm{a} 9 \mathrm{~h} \& \mathrm{AN}=683490 \&$ site=ehost-live

Martens, R. (1977). Sport Competition Anxiety Test. Champaign, IL: Human Kinetics Publishers.

Mohammed, A. (1991). Self-Concept for physically disabled adolescent. DAI, Cairo University.

Murphy, S. M., \& Jowdy, D. P. (1992). Imagery and mental practice. In T. S. Horn (Ed.), Advances in sport psychology, 221-250. Champaign, IL: Human Kinetics.

Noel, R.C. (1980). The effects of vi-quo-motor behavioral rehearsal on tennis performance. Journal of Sport Psychology, 2, 220-226

Onestak, D. (1997). The effect of Visuo-Motor Behavior Rehearsal (VMBR) and Videotaped Modeling (VM) on the Three-Throw Performance of Intercollegiate Athletes. Journal of Sport Behavior; 20 (2),185. [Online] Available: http://search.ebscohost.com/login.aspx?direct=true\&db=a9h\&AN=9707024951\&site=ehost-live

Petrie, T.A., \& Diehl, N.S. (1995). Sport psychology in the profession of psychology. Professional Psychology. Research and Practice, 26, 288-291. http://dx.doi.org/10.1037/0735-7028.26.3.288.

Suinn, R. (1972). Behavior rehearsal training for ski racers. Behavior Therapy, 3, 519. http://dx.doi.org/10.1016/S0005-7894(72)80191-6.

Suinn, R. (1976). Visual motor behavioral rehearsal for adaptive behavior. In I. Krumboltz \& C. Thoreson (Eds.), Counseling Methods, 360-366. New York: Holt.

Vealey, R. S., \& Walter, S. M. (1993). Imagery training for performance enhancement and personal development. In J. M. Williams (Ed.), Applied sport psychology: Personal growth to peak performance 200-224. Mountain View, CA: Mayfield.

Weinberg, R., Seabourne, T., \& Jackson, A. (1981). Effects of vi-quo-motor behavior rehearsal, relaxation, and 
imagery on karate performance. Journal of Sport Psychology, 3, 228-238

Weinberg, R., Seabourne, T., \& Jackson, A. (1982). Effects of vi-quo-motor behavior rehearsal on state-trait anxiety and performance: Is practice important? Journal of Sport Behavior, 5, 209-219

Wiggins, D.K. (1984). The history of sport psychology in North America. In J.M. Silva \& R.S. Weinberg (Eds.), Psychological foundations of sport, 9-22. Champaign, IL: Human Kinetics.

Zagacki, S., Edwards, R., \& Honeycutt, M. (1992). The Role of Mental Imagery and Emotion in Imagined Interaction. Communication Quarterly, 56-68. http://search.ebscohost.com/login.aspx?direct=true\&db=sih\&AN=18448593\&site=ehost-live

Zawawi, R. (1991). The effectiveness of the group guidance for training to solve problems and reduce anxiety, DAI, Jordanian University.

Table 1. Means and standard deviations for the dependent measures at pre- and post-test assessment times for the two conditions

\begin{tabular}{|l|l|l|l|l|}
\hline & $\begin{array}{l}\text { Experimental } \\
\text { group Pre }\end{array}$ & $\begin{array}{l}\mathrm{n}=32 \\
\text { Post }\end{array}$ & $\begin{array}{l}\text { Control } \\
\text { group Pre }\end{array}$ & $\begin{array}{l}\mathrm{n}=31 \\
\text { Post }\end{array}$ \\
\hline $\begin{array}{l}\text { Variable } \\
\text { TSCS }\end{array}$ & & & & \\
M & 66.43 & 71.50 & 66.90 & 65.80 \\
SD & 6.94 & 6.33 & 6.55 & 6.48 \\
Anxiety Scale & & & & \\
M & 133.18 & 82.47 & 81.52 & 91.10 \\
SD & 47.89 & 21.06 & 20.69 & 34.51 \\
\hline
\end{tabular}

Table 2. Means and standard deviations for the dependent measures at post-test assessment for the physical disabled and visual impairment

\begin{tabular}{|l|l|l|}
\hline & Physical disabled & Visual impairment \\
\hline Anxiety scale & & \\
M & 82.00 & 153.22 \\
SD & 21.80 & 39.59 \\
TSCS & & \\
M & 75.00 & 70.13 \\
SD & 6.9 & 7.1 \\
\hline
\end{tabular}

